\title{
Escolha Profissional do Adolescente Jovem: Pesquisa de Campo sobre as Interfaces do Apoio Parental
}

\author{
Sâmila Landim Moura ${ }^{\text {; }}$ Thercia Lucena Grangeiro Maranhão ${ }^{2}$
}

\begin{abstract}
Resumo: A realização da escolha profissional é permeada por diversos fatores que podem influenciar a decisão, dentre eles a família é visto como principal núcleo de aquisição de valores sobre o mundo de trabalho e de maior intervenção na realização da escolha. Diante disso o presente trabalho tem como objetivo o estudo sobre o impacto do apoio parental na escolha profissional mediante a análise do estilo parental e da decisão profissional. Para isso, será analisado os resultados de um questionário sobre o comportamento dos pais e escolha profissional. A pesquisa tem caráter quali-quantitativa e foi composta por 45 alunos concludentes do ensino médio com idade entre 18 e 19 anos que foram escolhidos por meio da amostra por acessibilidade. $\mathrm{Na}$ análise dos resultados foi utilizada a análise estatística na organização dos dados e a análise de conteúdo visando o aprofundamento nas questões de caráter subjetivo. Com os resultados da pesquisa infere-se que a combinação entre exigência e apoio dos pais (característicos do estilo autoritativo) constitui o contexto ideal para a decisão do adolescente jovem, sendo que a falta desse apoio (no estilo negligente e autoritário) pode dificultar a definição de metas e identificação de critérios importantes para a escolha, bem como evidenciaram que a dimensão de responsividade parental pode ter papel mais influenciador para a escolha do que a exigência dos pais quando esta encontra-se diminuída (no estilo indulgente).
\end{abstract}

Palavras-Chave: Escolha profissional; Estilos parentais; Adolescência.

\section{Professional Choices of the Young Adolescent: A Field Research on Parental Support Interfaces}

\begin{abstract}
The realization of the professional choice is permeated by several factors that can influence the decision, among them the family is seen as the main nucleus of acquisition of values about the world of work and of greater intervention in the realization of the choice. Therefore, the present study aims to study the impact of parental support on professional choice through the analysis of parental style and professional decision. For this, the results of a questionnaire on parental behavior and professional choice will be analyzed. The research has a qualitative and quantitative character and was composed of 45 concluding high school students aged 18 to 19 who were chosen through the sample for accessibility. In the analysis of the results was used the statistical analysis in the organization of the data and the analysis of content aiming at the deepening in the questions of subjective character. With the results of the research, it is inferred that the combination of parental demand and support (characteristic of the authoritative style) constitutes the ideal context for the young adolescent's decision, and the lack of such support (in the negligent and authoritarian style) goal setting and identification of important criteria for choice, as well as evidence that the parental responsiveness dimension may play a more influential role in the choice than the requirement of two parents when it is lessened (in the indulgent style).
\end{abstract}

Keywords: Professional choice; Parenting styles; Adolescence.

\footnotetext{
${ }^{1}$ Graduação em Psicologia pelo Centro Universitário Dr. Leão Sampaio, Brasil. Psicóloga CRP:11/1284.

E-mail; samilalandim91@gmail.com;

${ }^{2}$ Psicóloga. Professora da UNILEÃO. Mestra em Ciências da Saúde pela Faculdade de Medicina do ABC. Coordenadora da ABRH-CE Núcleo Cariri. E-mail: therciapsicologa@gmail.com
} 


\section{Introdução}

A escolha por um curso de graduação é permeada por diversos elementos que influenciam direta ou indiretamente na decisão. O ideal nesse processo é que o sujeito tenha um autoconhecimento que permita a identificação dos seus interesses e aptidões de forma que facilite a decisão sobre o que é melhor para si em consonância com o conhecimento sobre o mundo do trabalho e as profissões. Entretanto, o que geralmente acontece é uma definição da profissão a ser seguida com base na sugestão ou determinação de outrem.

Sobre os fatores que afetam a decisão profissional, tem-se a família como núcleo primário de aquisição de informações e valores sobre as profissões e o mundo do trabalho. Dessa forma pode-se afirmar que os pais adquirem o papel principal de interventores no processo da decisão realizado pelos filhos. Essa decisão pode ser facilitada ou dificultada pelos laços de apoio emocional existente entre os membros familiares (ANDRADE et al., 2016).

Percebendo-se a importância do contexto familiar surge a seguinte pergunta: quais os impactos subjetivos dos estilos parentais na decisão do jovem pela escolha profissional de uma escola do interior do Ceará? A partir do exposto, o trabalho versa sobre a associação entre estilos parentais e sua influencia na decisão do jovem estudante de ensino médio pela formação acadêmica e/ou ingresso no mercado de trabalho, apresentando assim como objetivo principal compreender a relação existente entre o apoio parental e a realização da escolha profissional. Com isso pretende-se apontar a relevância do tema no contexto acadêmico, buscando auxiliar no aprofundamento de estudos em Orientação Profissional e levando à reflexão sobre a indispensabilidade de considerar a influência dos pais no processo de escolha. Bem como possibilitar aos pais, docentes e demais profissionais que trabalham ou estudam procedimentos nessa vertente, uma compreensão maior de como auxiliar os jovens nessa decisão.

O trabalho iniciará com um estudo sobre o início da necessidade de escolha profissional, denotando a importância dos processos de orientação profissional, o surgimento dessas práticas e as principais técnicas utilizadas atualmente. Em seguida, serão apontados aspectos do período de vida do qual trata a pesquisa, a saber, a adolescência e juventude e suas singularidades. No terceiro tópico serão especificadas questões relevantes à escolha profissional que acontece no final da adolescência e posteriormente será evidenciado a participação dos pais e os impactos que podem acarretar na decisão dos filhos. Por fim, será explicada a metodologia e aspectos práticos que envolvem o estudo. Após explicação dos métodos e procedimentos, serão 
apresentados os resultados obtidos na pesquisa, seguido da análise dos conteúdos encontrados. O trabalho obteve aprovação no Comitê de Ética e Pesquisa, com o parecer do CAAE de número 792444172405048 .

\section{Escolha Profissional}

A opção por uma escolha profissional é relativamente recente, pois embora o trabalho exista desde o início da sociedade, a necessidade de aprimorar-se e profissionalizar-se é nova, tendo em vista que antigamente os trabalhos eram herdados do clã, família, ou grupo social à qual o indivíduo pertencia. Com as mudanças no mundo do trabalho, intensificadas com a industrialização, surgiu a necessidade da especialização da mão-de-obra (NEIVA, 2013; LIMA, 2007).

A Orientação Vocacional, conforme Aguiar e Conceição (2013), teve seu início marcado principalmente pela Psicometria, tendo expansão no período da Revolução Industrial, no final do século XIX. Na época, o objetivo era encontrar o trabalhador ideal para cada cargo a fim de obter-se melhor eficácia no trabalho e maior lucro para os empregadores. Além disso, acreditava-se que o trabalhador que estivesse empregado em um cargo adequado para ele, que seria escolhido com base nas suas características e aptidões inatas, estaria satisfeito, ajustado, e isso seria fator motivador para o bom desempenho no trabalho.

O modelo Psicométrico, que foi um dos responsáveis pelo avanço da psicologia e reconhecimento da profissão enquanto ciência teve maior desenvolvimento nos períodos da $1^{\mathrm{a}}$ e $2^{\mathrm{a}}$ guerras mundiais, tendo grande influência da Teoria do Traço e Fator, de Frank Parsons, motivo pelo qual muitos o consideram como "pai” da Orientação Vocacional. Aliando a isso existia a preocupação com a higiene mental predominante na época, isto possibilitou que o uso dos testes utilizados para determinar a ocupação do sujeito ganhasse força, visto que a inserção em um trabalho no qual estivesse adaptado era considerado como preventivo. Esse período pode ser considerado como uma primeira fase da Psicologia Vocacional, tendo durado de 1900 à 1950 (NEIVA, 2013; LIMA, 2007).

A segunda fase da Orientação Vocacional, compreendida a partir da década de 1950 até os dias atuais, contou com diversas teorias que influenciaram as técnicas utilizadas. Carl Rogers é considerado como um dos principais teóricos apontados para a mudança nas práticas vigentes, 
pois com as concepções apresentadas na Teoria Centrada no Cliente propôs um método nãodiretivo que valorizava a participação do sujeito no processo (ANDRADE et al., 2016).

No Brasil, o trabalho com Orientação Vocacional teve inicio em 1924 por meio da atuação do professor Roberto Mange no Liceu de Artes e Ofícios de São Paulo e, em 1931, Lourenço Filho criou o primeiro Serviço de Orientação Profissional. Inicialmente era responsabilidade dos psicólogos as atividades de orientação, tendo ganhado posteriormente o espaço entre os profissionais da educação (NEIVA, 2013; ANDRADE et al., 2016).

Um dos principais teóricos que contribuíram para a mudança do predomínio modelo psicométrico para o clínico no Brasil foi o argentino Rodolfo Bohoslavsky, que ampliou a partir da década de 70 as ideias presentes até então. Para ele deveria-se resgatar os valores e prezar pelos sentimentos na escolha, valorizando o indivíduo enquanto pessoa e sua autonomia, levando-o à formação de uma identidade própria (FEIJOO; MAGNAN, 2012).

Apesar da maior parte dos estudos utilizarem a nomenclatura Vocacional e Profissional pra definir os mesmos tipos de intervenções, há entre alguns autores a distinção entre os termos, compreendendo a Orientação Vocacional como processo mais ampliado que valoriza os aspectos inatos do indivíduo, suas aptidões para determinada profissão. Dessa forma a Orientação Vocacional é compreendida como um conjunto de técnicas que tem como objetivo promover o autoconhecimento e conhecimento acerca das oportunidades profissionais de forma a favorecer uma escolha consciente e autônoma, bem como a evitação de frustrações profissionais futuras (LIMA, 2007).

Atualmente, há a utilização dos dois modelos na psicologia: o psicométrico e o clínico. Neiva (2013) conceitua o modelo psicométrico que teve origem nos primórdios da psicologia como Atuarial ou Estatístico, que se baseia na utilização de uma bateria de testes psicológicos que avaliam aspectos como a personalidade, as habilidades específicas e capacidade intelectual. Esse modelo é comumente criticado pelo fato de geralmente não envolver o orientando no processo, visto que esse pode adotar uma postura passiva e não refletir sobre sua decisão, deixando-se muitas vezes ser guiado apenas pelos resultados apontados no teste. Outra fragilidade do modelo está no fato de não existir uma pesquisa acerca da realidade socioprofissional do contexto onde está inserido, desconsiderando as novas profissões que surgem e as mudanças no mercado de trabalho.

Já o modelo clínico tem como objetivo principal que o sujeito desenvolva uma identidade vocacional-ocupacional e uma autonomia que possibilite a melhor escolha, enquanto 
o orientando assume uma postura ativa, o orientador age como facilitador do processo. A principal técnica nesse modelo é a entrevista, embora possam ser utilizados dinâmicas, jogos e testes, a única ressalva é que os resultados obtidos com a utilização de testes sejam discutidos com o orientando. $\mathrm{O}$ método utilizado baseia-se principalmente na escuta e no diálogo entre ambas as partes, dessa forma o orientando pode escutar-se, refletir e elaborar suas questões. Há na perspectiva clínica o contato com o contexto em que o indivíduo encontra-se inserido, levando em conta dessa forma o aspecto cultural e socioprofissional, pois tem a busca de informações sobre profissões, mercado de trabalho e cursos superiores, objetivando com isso o conhecimento das profissões e a desconstrução de fantasias preexistentes (NEIVA, 2013; LIMA, 2007).

De acordo com Neiva (2013), o modelo clínico pode também ser utilizado em grupos, que se mostram muito eficazes no trabalho dentro das instituições. A autora afirma que para tal há o uso das obras de Pichon-Riviere como apoio no que diz respeito aos grupos operativos, onde o grupo tem como objetivo a resolução de um problema comum a todos, permitindo a troca de experiências e sentimentos entre o grupo. Nesse caso, o orientador atua como coordenador, sendo necessária uma cautela em relação à quantidade de membros do grupo para que possa dar conta. Grupos maiores requerem a participação de dois coordenadores.

A prática de Orientação Vocacional influenciada pela corrente Fenomenológica Existencial refere-se a um processo que valoriza a liberdade do indivíduo no processo de construção e desconstrução das perspectivas profissionais, criticando a postura que valoriza aspectos internos (aptidões inatas) e externos (sociedade), colocando o sujeito como dividido. Com isso busca-se um trabalho onde o ser é considerado em sua totalidade, construindo todo o processo. Aqui as atividades não são previamente planejadas, mas são realizadas de acordo com o que é discutido em cada encontro e aparece como necessidade (FEIJOO; MAGNAN, 2012).

\section{Adolescência e Juventude}

A adolescência é considerada como a fase de vida que marca a transição entre a infância e a vida adulta, de acordo com o Estatuto da Criança e do Adolescente no artigo $2^{\circ}$ da Lei n. ${ }^{\circ}$ 8.069, de 13 de julho de 1990, a adolescência é considerada como o período de vida que compreende as idades de 12 a 18 anos. Já o Ministério da Saúde considera o que foi proposto 
pela Organização Mundial de Saúde (OMS), que compreende a adolescência como a fase que vai dos 11 aos 19 anos e a juventude entre 15 e 24 anos, sendo que o intermédio dos 15 aos 19 é conceituado como adolescente jovem, e dos 20 aos 24 como adultos jovens (BRASIL, 2005).

Devido à variedade dos fenômenos psicossociais que marcam essa fase de vida, o Ministério da saúde utiliza a nomenclatura "adolescências e juventudes", ou ainda "pessoas jovens", numa abrangência geral. A utilização do termo no plural é justificado pelo fato da presença de distintos elementos que resultam em uma multiplicidade de experiências que são afetadas pelo nível socioeconômico, por questões étnico-raciais, religiosas, culturais, de gênero e de orientação sexual (BRASIL, 2010).

Conforme Papalia, Olds e Feldman (2010), a adolescência é uma construção social que acontece posteriormente ao início da puberdade, onde a criança passa por mudanças que a levam à maturidade sexual e à capacidade de reprodução, ocasionando mudanças físicas no corpo que antes era infantil. Ao passo que a puberdade é reconhecida mundialmente, o período da adolescência vem se globalizando com o passar dos anos, sendo mais acentuado como fase de transição no mundo ocidental.

Sobre compreensão da adolescência enquanto período de vida entende-se como recente, pois na era pré-industrial só existiam adultos e crianças, e a alteração de uma fase para outra era reconhecida a partir das mudanças físicas ou quando a criança começava a aprender algum ofício. Sendo assim, a terminologia "adolescência" surge na segunda metade do século XX, quando, em detrimento da grande quantidade de órfãos em decorrência da Segunda Guerra Mundial, especialistas passaram a observar e estudar as singularidades desse período (PAPALIA; OLDS; FELDMAN, 2010; VELHO; QUINTANA; ROSSI, 2014).

Considera-se que a principal característica da adolescência e juventude consiste no que Eric Erikson (1998), chamava de "busca pela identidade", na qual se tem a tarefa de encarar a crise identidade x confusão de identidade, que perpassa por três etapas principais: a definição de uma ocupação, a adoção de valores nos quais se baseará nas suas escolhas de vida, e a aquisição de uma identidade sexual satisfatória.

Outro fato que é considerado como pertinente a esse período de vida encontra-se na busca de maior autonomia, posto que na infância há uma dependência maior dos pais que passa a não ser tão esperada enquanto aproxima-se da idade adulta, em decorrência disso observa-se um distanciamento progressivo das figuras paternas e uma exigência maior da sociedade de 
auto-responsabilização do adolescente (BRASIL, 2010 ; VELHO; QUINTANA; ROSSI, 2014).

Constata-se no entendimento da adolescência que existe uma tendência a naturalizar manifestações como rebeldia ou atos inconsequentes como "normais" ao período de vida, conforme mostra a pesquisa de Melo e Cruz (2014), na qual o Conselho Federal de Psicologia (2002) percebe a presença do que teóricos conceituam como "síndrome normal da adolescência".

Sobre essa naturalização de fenômenos da adolescência, o Conselho Federal de Psicologia (2002), enfatiza que deve haver por partes dos psicólogos uma postura que vá de encontro a essas concepções que naturalizam e patologizam o indivíduo, compreendendo-se o sujeito enquanto ser sócio-histórico, na qual situações de rebeldia, moratória, instabilidade, busca de identidade e os conflitos encontram respostas na contradição entre as exigências impostas pela sociedade capitalista e os recursos sociais que os jovens dispõem.

Corroborando com o que é posto pelo CFP, o Ministério da Saúde evidencia que esse período é marcado pelo processo de emancipação que está além da passagem da escola para o mercado de trabalho que é afetada diretamente ao perpassar pelas dimensões macrossociais (desigualdades de classe, gênero, etnia), institucionais (sistemas de ensino e mercado de trabalho) e biográficas (particularidades e história de vida de cada indivíduo), por isso eles tem necessidade de ser ouvidos e compreendidos, sendo preciso enxergá-los como cidadãos, sujeitos de plenos direitos, que podem e devem se posicionar nos diversos âmbitos do cotidiano onde então inseridos (BRASIL, 2010).

\section{Escolha Profissional na Adolescência e Juventude}

Embora a escolha profissional possa ocorrer nas diversas fases da vida, encontra-se presente de forma intensa e comumente mais conflitante no período da adolescência, especificamente no momento em que estão concluindo o ensino médio e são pressionados a optarem entre continuar ou não os estudos por meio do ingresso no ensino superior, e no caso dos que almejam a graduação há a dúvida de qual curso seguir.

Há nessa fase que compreende a adolescência, uma série de transformações que são influenciadas por aspectos socioculturais que afetam diretamente a singularidade de cada 
indivíduo, levando-o a reformulações das concepções de caráter social, sexual e de gênero, ideológico e vocacional (BRASIL, 2005).

O ideal é que o sujeito jovem adquira uma identidade vocacional-ocupacional, que consiste na escolha da profissão a seguir, bem como o porquê dessa decisão. Porém durante o processo pode acontecer a formação de transtornos, que podem ser transitórios ou permanentes, por meio da construção de identidades negativas ou pseudoidentidades. Na identidade negativa, o sujeito pode identificar-se com aspectos indesejados pela família ou grupo social que faz parte, adquirindo valores que vão contra os aceitos pelos demais que o cercam. É comum a identificação com personagens ou grupos marginalizados, a isso dá-se o nome de identificação com o agressor. Já na pseudoidentidade, a escolha profissional é uma máscara, pois o sujeito não elabora sua identidade, mas segue o que os outros valorizam ou sugerem, sem uma deliberação (NEIVA, 2013).

Um dos pontos que configura especificidade da escolha nesse período de vida é enfatizado por Gimenes et al., (2015), pois conforme a autora, há na adolescência uma visão da escolha profissional como algo definitivo, além disso há uma pressão exercida pela família e sociedade de que o adolescente não pode perder tempo, colocando ainda que o distanciamento presente entre escola e universidade pode ser um elemento que dificulte a escolha, pois os adolescentes necessitam de informações para uma decisão mais reflexiva.

Para Lima (2007), é fundamental compreender as cobranças da sociedade e a pressão da família como fatores que podem levar o jovem a desorientar-se temporariamente, todavia é necessário a presença e apoio dos familiares e amigos, visto que a omissão do outro, principalmente dos familiares, pode causar revolta. A autora traz ainda que nessa fase o jovem está muito mais ligado aos grupos de iguais, a opinião e valores dos colegas de mesma faixa etária são considerados no processo de escolha e possibilitam a manutenção ou mudança de comportamentos.

O Ministério da Saúde afirma que é necessário oferecer aos jovens a possibilidade de atividades que garantam o seu desenvolvimento, tais como o acesso aos serviços de saúde, à educação formal, às atividades recreativas, ao desenvolvimento vocacional e às oportunidades de trabalho. Assim como necessita ser ouvido e ter sua autonomia respeitada (BRASIL, 2010).

A elaboração da identidade é um processo que tem como alicerce o autoconhecimento e a autonomia, é preciso se responsabilizar pela escolha feita e pelo projeto de vida que se almeja seguir. É um percurso que acontece em rede, com as interações sociais e o diálogo, por 
isso pode-se considerar o modelo de orientação vocacional clínico, seja em grupo ou individual, como importante contribuinte da escolha, sendo que a escola pode ser o local ideal para estímulo e desenvolvimento da prática (BRASIL, 2010; AGUIAR; CONCEIÇÃO, 2013).

\section{Escolha Profissional e Estilos Parentais}

De acordo com Andrade et al., (2016) o momento de escolha profissional, apesar de não ser restrita apenas à adolescência, é considerado como mais crítico nessa fase devido às mudanças e crise peculiares desse período de vida. Considerando que a família é importante para o desenvolvimento psicossocial do adolescente, é necessário refletir sobre sua influência, visto que o adolescente, no enfrentamento de sua crise de visão de mundo, pode não conseguir distinguir seus desejos dos desejos paternos.

É importante ressaltar que para Erik Erikson (1998), as crises surgem em diferentes etapas, e a resolução satisfatória de cada crise representam a aquisição de valores importantes para a vida, no caso específico da adolescência, com a resolução da crise deve emergir a construção de uma identidade, onde o valor encontrado é o da fidelidade, dependendo dele a confiabilidade do comprometimento do jovem adulto.

A família é vista como o principal influenciador e muitas vezes fator determinante para os jovens que ingressaram ou almejam ingressar na faculdade, visto que é no seio familiar que acontece de forma mais efetiva a percepção de si e do mundo, bem como a aquisição de crenças e valores, inclusive sobre o mundo do trabalho (ANDRADE et al., 2016; MAGALHAES; ALVARENGA; TEIXEIRA, 2012; OLIVEIRA; DIAS, 2013).

Os valores transmitidos pela família podem ser interiorizados e considerados pelo sujeito, ou rejeitados, fazendo com que o jovem opte por ir na contramão do que os familiares esperam (NEIVA, 2013). A aceitação ou rejeição dos valores familiares podem estar diretamente ligadas aos estilos parentais, que são preponderantes no desenvolvimento dos filhos desde o período escolar até o momento de escolha profissional (PRATA et al., 2013).

O conceito de estilo parental foi proposto por Baumrind em 1966, referindo-se a forma como os pais lidam com poder, hierarquia e apoio emocional em relação aos filhos e como isso interfere no ajustamento social e no desempenho escolar (PRATA et al., 2013). Baumrind definiu três estilos, a saber: estilo autoritativo, estilo autoritário e estilo permissivo. O primeiro 
estilo (também chamado de democrático) é baseado no respeito entre os pares e nos valores sociais, na qual os pais buscam fornecer orientação aos filhos, sendo considerado o modelo ideal. No segundo estilo é enfatizada a importância do controle e obediência, estabelecendo-se regras que devem ser rigorosamente seguidas sem questionamentos, não existe um diálogo entre os pares, mas uma imposição de padrões e uma alta exigência em relação ao seu cumprimento. Por fim, no estilo permissivo há pouca exigência e monitoramento dos pais em relação aos filhos (MAGALHAES; ALVARENGA; TEIXEIRA, 2012).

Posteriormente Maccoby e Martin reorganizaram em 1983 os estilos propostos por Baumrind por meio da análise de duas dimensões: a exigência e a responsividade, no qual o primeiro ressalta as atitudes de estabelecimento de limites e controle por parte dos pais, e o segundo a compreensão e apoio emocional que são dados aos filhos. Com base nas combinações dessas dimensões tem-se quatro estilos parentais distintos: Autoritativo (alta exigência e responsividade), Autoritário (alta exigência e baixa responsividade), Indulgente (baixa exigência e alta responsividade) e Negligente (baixa exigência e responsividade) (MAGALHAES; ALVARENGA; TEIXEIRA, 2012).

Uma classificação diferente é feito por Neiva (2013), que enfatiza três posturas dos pais frente à escolha profissional dos filhos: Pressionadora, Ausente ou Facilitadora. Nas famílias pressionadoras há uma pressão, que pode ser enfática ou sutil, para que o filho siga determinada profissão, levando-o a representar o papel de depositário das ambições, frustrações e desejos dos familiares. Nas famílias ausentes os pais não participam, nem tampouco se interessam pelas escolhas dos filhos, o que pode gerar um sentimento de abandono e revolta. Em ambos os casos, famílias pressionadoras ou ausentes, há um efeito negativo sobre os filhos. Já nas famílias do tipo facilitadoras, há uma relação aberta permeada pelo respeito, no qual há o acompanhamento diante da escolha e o incentivo a um trabalho de Orientação Profissional, resultando em uma escolha madura e autônoma dos jovens.

Magalhães, Alvarenga e Teixeira (2012), discorrem sobre a importância da idealização dos pais como fator importante para inspiração de ideais e metas de vida que possibilitem a criação de um compromisso com suas escolhas, caso isso não aconteça, o jovem tende a não se comprometer com planos reais, permanecendo em uma fase de moratória. Sobre isso, o estudo realizado por Oliveira e Dias (2013) permitiu identificar que os jovens universitários eram influenciados pelos exemplos dos pais, no qual a percepção da satisfação ou insatisfação dos 
pais com o trabalho que realizam constitui fator relevante na construção da carreira dos universitários.

Conforme Magalhães, Alvarenga e Teixeira (2012), as famílias autoritárias prejudicam os filhos na decisão pela carreira, visto que os adolescentes tendem a construir uma autoimagem negativa e tornam-se dependentes e indecisos em relação ao futuro. Famílias permissivas estão associadas à negligência, o que tem consequências desfavoráveis para os adolescentes. As famílias autoritativas mostram-se favoráveis para a escolha profissional, pois geralmente os filhos que contam com o apoio dos pais desenvolvem autonomia e compromisso com suas escolhas.

\section{Metodologia}

\section{Método de Pesquisa}

O projeto utiliza-se de uma metodologia quali-quantitativa, trata-se de uma pesquisa de campo, que segundo Prodanov e Freitas (2013), consiste em um método que busca a observação de fatos e coleta de dados com finalidade de analisar a relação entre diferentes fenômenos, sendo para tal necessário um levantamento bibliográfico realizado anteriormente, a escolha das técnicas de coletas das informações e a interpretação dos dados obtidos.

\section{Instrumento}

O trabalho foi desenvolvido com a aplicação de um questionário com questões objetivas e subjetivas. Conforme Raposo (2011), o uso de questionários em pesquisa é uma técnica na qual há a elaboração de um conjunto de perguntas que visa analisar atitudes, opiniões e comportamentos, além de obter como vantagem a garantia do anonimato e a possibilidade de atender às finalidades específicas da pesquisa.

O questionário foi composto de doze questões situacionais objetivas, as seis primeiras visando investigar a dimensão associada à exigência paterna, e as seis seguintes associadas a responsividade dos pais, conforme mostram as Tabelas 1 e 2 . 
Tabela 1. Dimensão de Exigência

Questões da dimensão Exigência

1. Meus pais estabelecem/estabeleciam regras a serem seguidas sem explicação

2. Meus pais costumam controlar meus horários e rotinas diárias.

3. Tenho dificuldades de manter o diálogo com meus pais.

4. Costumo me sentir cobrado (a) em relação aos estudos por meus pais.

5. Meus pais costumam determinar as escolhas que eles desejam que eu faça.

6. Meus pais costumam me punir por minhas atitudes.

Fonte: Autoras, 2017

Tabela 2. Dimensão de Responsividade

Questões da dimensão Responsividade

7. Meus pais me incentivam a ser esforçado.

8. Sinto que posso contar com o auxilio dos meus pais caso esteja enfrentando algum problema

9. Meus pais me procuram pra convesar.

10. Meus pais incentivam minha independência e autonomia.

11. Meus pais costumam reconhecer quando faço algo bom

12. Meus pais apóiam minhas escolhas

Fonte: Autoras, 2017

Para cada alternativa das questões objetivas foram colocadas quatro opções de respostas: sempre, muitas vezes, poucas vezes e nunca, na qual o participante deveria assinalar a alternativa que apresentasse a frequência com que a situação descrita costumava acontecer.

Por fim foram elaboradas cinco questões abertas que buscaram apurar dados associados à escolha profissional, valores do mundo do trabalho e contribuição dos pais na escolha, para fim de análise estão presentes na Tabela 3.

Tabela 3. Questões sobre escolha profissional, valores do mundo do trabalho, participação dos pais.

13. O que você pretende fazer ao concluir o ensino médio?

14. Alguém o incentiva na sua decisão profissional, se sim, de que modo?

15. Você pretende cursar o ensino superior? Se a resposta for positiva, qual curso você tem em mente e por quais motivos o escolheu?

16. Quais critérios você considera importante para realização da escolha profissional?

17. Como você vê a participação dos seus pais na sua escolha profissional?

Fonte: Autoras, 2017 


\section{Participantes}

A escolha dos participantes foi realizada com uma amostra por acessibilidade, formado por 45 alunos, sendo $31(68,9 \%)$ do sexo masculino e 14 (31,1\%) do sexo feminino, com idade entre 18 e 19 anos que cursavam o $3^{\circ}$ ano do ensino médio, sendo $29(64,4 \%)$ do turno matutino e 16 (35,6\%) do vespertino. Conforme Prodanov e Freitas (2013), esse é um tipo de amostragem comum em pesquisas de caráter qualitativo, onde o pesquisador seleciona os elementos a que obtém acesso, sendo considerada adequada ao trabalho visto a limitação de idade objetiva da pesquisa.

\section{Procedimento}

A pesquisa foi aplicada após o consentimento dos participantes, em sala disponibilizada pela escola, contando com cadeiras e mesas para comodidade ao fazer o preenchimento dos questionários. Participaram do estudo alunos de diferentes turmas, sendo aplicado no horário matutino com 29 alunos e no vespertino com 16. Inicialmente foi realizada a explicação da pesquisa e dos questionários, com tempo disponível para que os alunos tirassem suas dúvidas. Sendo posteriormente entregue o questionário. A aplicação pela manhã teve duração de 30 a 40 minutos, e de 20 a 30 minutos pela tarde. A pesquisa foi redigida com base na Resolução N $^{\circ}$ 466/2012 e na Resolução No 510/2016 do Conselho Nacional de Saúde, que dispõe sobre a ética do pesquisador e acerca do respeito pela dignidade humana e pela proteção dos participantes em pesquisa científicas. O trabalho foi apresentado ao Comitê de Ética e Pesquisa, obtendo parecer favorável com número do CAAE 792444172405048.

\section{Análise dos Dados}

O estudo dos dados obtidos na pesquisa foi realizado por meio de uma análise estatística nos dados quantitativos, que de acordo com Marconi e Lakatos (2011), permite analisar conjuntos complexos e as relações existentes entre elementos, além de fornecer um todo 
organizado dos aspectos quantitativos da população pesquisada. Desse modo as alternativas foram pontuadas de 0 a 3 de acordo com a frequência de acontecimento da situação descrita, sendo 3 a pontuação relativa ao item "sempre" e 0 ao item "nunca". As respostas de ambas as dimensões foram calculadas e consideradas acima de 9 uma elevada dimensão de exigência e/ou responsividade, e abaixo de 9 responsividade e/ou exigência reduzidas. Com base nos resultados obtidos na pontuação das dimensões dividiu-se os participantes de acordo com o Estilo Parental encontrado, conforme mostra a Tabela 4 e 5 dos resultados.

Nas questões de caráter qualitativas foi utilizada como metodologia a análise de conteúdo, que conforme Shaughnessy, Zechmeister e Zechmeister (2012), é comum em pesquisas de caráter qualitativo, requerendo a realização de uma redução de dados por meio da seleção de comportamentos que serão analisados pelo pesquisador e mostrados na pesquisa. Para tal será feito a transcrição de algumas respostas com fim de evidenciar os aspectos a serem estudados.

Como os questionários são anônimos com objetivo de proteger a confidencialidade dos participantes, cada formulário foi numerado de 1 a 49. Dessa forma, ao apresentar os conteúdos, a identificação será feita pelo número do aluno para possibilitar a análise e distinção entre as respostas.

\section{Resultados e Discussão}

Os critérios apontados como necessários para a decisão profissional e os motivos que os participantes utilizaram para justificar as profissões desejadas podem ser um indicativo do que foi colocado por Gimenes et al., (2015), ao apontar que a influência dos pais pode acontecer como uma pressão por uma escolha, independente de qual for, ou como uma expectativa por uma profissão específica que traga reconhecimento profissional e estabilidade financeira, ou por algo que continue o legado da família. A seguir serão apresentados os principais resultados encontrados por estilo parental na ordem apresentada na Tabela 4, que mostra os resultados dos estilos parentais encontrados na amostra da pesquisa. 
Tabela 4. Quantidade de Estilos Parentais da amostra

\begin{tabular}{ccc}
\hline Estilos Parentais & Quantidade & Porcentagem \\
\hline Autoritário & 1 & 2,2 \\
Negligente & 3 & 6,7 \\
Autoritativo & 16 & 35,5 \\
Indulgente & 25 & 55,5 \\
\hline
\end{tabular}

Fonte: Autoras, 2017

Como é possível observar pelas tabela, o estilo parental que apareceu com maior freqüência dentro da amostra selecionada foi o indulgente (correspondente a 55,5\%), seguido pelo autoritativo $(35,5 \%)$, negligente $(6,7 \%)$ e autoritário $(2,2 \%)$.

O estilo parental de pais autoritários que são caracterizados por apresentar alta exigência e pouco afeto e apoio, foi observado apenas no estudante 37, que afirmou estar dividido entre três cursos, citando apenas dois de áreas distintas (psicologia e música), o que talvez revele uma instabilidade de metas, mesmo justificando a escolha como amor pela música e desejo de compreender o ser humano. Além disso, revelou na questão 17 que não tinha apoio dos pais porque eles não tinham conhecimento de sua decisão, contando com incentivo apenas de professores e amigos. Como critérios para a escolha profissional o estudante apontou que buscava uma carreira que lhe desse segurança, certeza e que tivesse incentivo de terceiros. $\mathrm{Na}$ questão 17, acerca da participação dos pais na escolha, escreveu: "Sem influência. Eles querem que eu trabalhe obviamente mas não tenho certeza se eles me vêem fazendo uma faculdade (sic)". Tal afirmação pode denotar um receio de tratar de tais questões com os pais, e/ou a falta de comunicação comuns desse estilo, o que prejudica a escolha tendo em vista a necessidade de apoio percebida pelo próprio sujeito.

O estilo parental negligente foi encontrado em três estudantes, dois de sexo masculino (alunos 11 e 17) e um de sexo feminino (aluna 28). Os três alunos foram vagos nas respostas. Dois apontaram querer cursar ensino superior, com a escolha já realizada, mas um sem justificativa (aluno 11) e outra (aluna 28) afirmando na questão 15 querer cursar Direito por ser uma profissão fácil de conseguir emprego e por gostar, o estudante 17 afirmou não querer cursar ensino superior e planeja trabalhar. Sobre o incentivo, dois estudantes (28 e 17) colocaram que tinham apoio, no entanto não falaram de quem ou como acontecia. Acerca dos critérios para a 
escolha, um questionário foi deixado em branco (aluno 17), um respondido vagamente e erroneamente com "muita dedicação, esforço ao maxímo" (aluna 28) e um que afirmou sobre a importância da identificação, apontado que "fazer o que você gosta" (sic aluno 11) seria o ideal. Sobre a participação paterna, um questionário foi deixado em branco (aluno 17) e os outros escreveram “eles não se manifestam” (sic aluna 28) e "eles não se importam” (sic, aluno 11).

Os resultados obtidos nas questões subjetivas encontradas nos filhos de pais negligentes corroboram para o que foi colocado por Magalhães, Alvarenga e Teixeira (2012), ao apontarem em sua pesquisa que filhos de pais negligentes possuem dificuldades de estabelecer metas e prejuízos no desenvolvimento biopsicossocial, visto a carência na identificação de critérios importantes e falta de reflexão sobre os fatores que motivam a escolha. Estando de acordo com o que foi posto por Oliveira e Dias (2016), pois segundo os autores, a liberdade de decisão sem o apoio dos pais pode gerar insegurança e insatisfação na realização da escolha.

No estilo parental autoritativo foram encontradas respostas diferentes, mas que convergem para uma boa reflexão acerca da escolha. Cabe ressaltar também que nesses participantes, foram encontradas respostas mais completas no questionário, o que talvez caracterize o bom desempenho escolar e desenvolvimento do adolescente que é comum a filhos de pais com esse estilo parental. Na Tabela 5 serão apontadas as respostas encontradas entre os alunos.

Tabela 5. Resumo de respostas encontradas por filhos de pais autoritativos.

\begin{tabular}{lllll}
\hline Questões & \multicolumn{4}{c}{ Respostas } \\
\hline 13 & 1 aluno pretende trabalhar & $\begin{array}{l}\text { 15 alunos pretendem ingressar no ensino } \\
\text { superior }\end{array}$ \\
14 & 4 alunos afirmaram não ter incentivo & 12 alunos afirmaram ter incentivo \\
15 & $\begin{array}{l}1 \text { aluno não citou o curso } \\
\text { apesar de confirmar querer } \\
\text { ingressar na faculdade. }\end{array}$ & $\begin{array}{l}1 \text { aluno pretende } \\
\text { fazer um curso de } \\
\text { qualificação }\end{array}$ & $\begin{array}{l}\text { divididos entre } 2 \text { alunos estão } \\
\text { cursos }\end{array}$ & $\begin{array}{l}12 \text { alunos têm } \\
\text { um curso } \\
\text { definido }\end{array}$ \\
16 & $\begin{array}{llll}\text { Apenas 1 aluno não definiu critérios para a escolha profissional } \\
17\end{array}$ & Todos afirmaram ter uma boa participação e/ou apoio dos pais & \\
\hline
\end{tabular}

Fonte: Autoras, 2017 
Nos resultados identificados nos filhos de pais autoritativos, no qual se encontra uma boa combinação entre o apoio parental e a exigência e imposição dos limites com estabelecimento do diálogo, todas as respostas convergiram para a realização consciente de uma escolha, visto que dos dezesseis alunos encontrados, apenas o aluno 6 não pretende ingressar no ensino superior, mas tem objetivo de fazer um curso de qualificação para aprimorar suas habilidades no emprego. Somente um participante não citou a faculdade (aluno 18) e dois alunos permanecem indecisos entre dois cursos. Entretanto, em um deles (aluno 7) as duas faculdades pensadas encontram-se na mesma área do conhecimento (psicologia e medicina), estando aliadas a saúde e sendo apontadas pelo desejo de ajudar o outro, já no segundo caso o aluno justificou querer cursar uma faculdade para ter uma boa renda financeira (engenharia da computação) e outra por gostar da área (música), que apesar de revelarem um dificuldade de clarificação no conhecimento sobre a profissão, evidenciam uma clareza de metas bem definidas. Entre os catorze alunos que já tem um ou dois cursos definidos, quatro não justificaram a escolha e dez colocaram como motivação a identificação com a área e a remuneração financeira.

Sobre critérios para a escolha, apenas um estudante não apontou quais seriam. Foram encontradas respostas que apontam para necessidade de realização pessoal, estabilidade financeira, escolha de uma universidade renomada e algumas respostas associadas ao mérito do esforço e dedicação, o que pode indicar uma escolha por algo que garanta o reconhecimento do sujeito.

Como é possível observar na tabela, mesmo os alunos que afirmaram não terem incentivo para a escolha profissional, todos apontaram ter uma boa participação dos pais, surgindo respostas como "Vejo que ficam felizes e me apóiam e me ajudam de todas as formas" (sic aluna 40); "Participação dos meus pais é muito importante, pois ele me incentiva e me dá todo o suporte que eles podem." (sic aluno 7); "Eles hoje participam muito incentivam e não medem esforços para que eu consiga!" (sic aluna 26) e "Fico muito feliz por eles me apoiar" (sic aluno 18). Tais respostas demonstram não apenas o reconhecimento dos estudantes em relação ao apoio paterno, como também uma satisfação pessoal por esse suporte oferecido.

O estilo parental indulgente foi encontrado em cerca de $55 \%$ dos participantes, havendo divergências entre respostas bem elaboradas e questionários vagos. Também foram encontradas contradições presentes nas respostas, o que talvez aponte para uma fraca criação de metas 
profissionais ou para o reflexo de uma maior influência de terceiros. A Tabela 6 apresenta um resumo das principais respostas encontradas.

Tabela 6. Resumo de respostas encontradas por filhos de pais indulgentes.

\begin{tabular}{|c|c|c|c|c|c|c|c|c|c|c|}
\hline \multirow[b]{2}{*}{$\frac{\text { Questões }}{13}$} & \multicolumn{10}{|c|}{ Respostas } \\
\hline & $\begin{array}{l}1 \text { aluno } \\
\text { quer } \\
\text { estudar } \\
\text { para } \\
\text { concurso }\end{array}$ & $\begin{array}{l}3 \text { alunos } \\
\text { querem } \\
\text { trabalhar }\end{array}$ & $\begin{array}{l}13 \\
\text { que } \\
\text { ent } \\
\text { fact }\end{array}$ & $\begin{array}{l}\text { alunos } \\
\text { rem } \\
\text { rar na } \\
\text { uldade }\end{array}$ & $\begin{array}{l}1 \text { alu } \\
\text { quer } \\
\text { cresc } \\
\text { You' }\end{array}$ & $\begin{array}{l}\text { no } \\
\text { er no } \\
\text { Tube }\end{array}$ & $\begin{array}{l}5 \text { al } \\
\text { que } \\
\text { trab } \\
\text { entr } \\
\text { facu }\end{array}$ & $\begin{array}{l}\text { s } \\
\text { ar e } \\
\text { ha } \\
\text { de }\end{array}$ & $\begin{array}{l}1 \text { aluno } \\
\text { não } \\
\text { respondeu }\end{array}$ & $\begin{array}{l}1 \text { aluno } \\
\text { quer fazer } \\
\text { curso } \\
\text { técnico ou } \\
\text { superior }\end{array}$ \\
\hline 14 & \multicolumn{2}{|c|}{$\begin{array}{l}21 \text { alunos } \\
\text { afirmaram ter } \\
\text { incentivo }\end{array}$} & \multicolumn{3}{|c|}{$\begin{array}{l}2 \text { alunos } \\
\text { afirmaram não ter } \\
\text { incentivo }\end{array}$} & \multicolumn{3}{|c|}{$\begin{array}{l}1 \text { aluna disse } \\
\text { que as vezes } \\
\text { tem incentivo }\end{array}$} & \multicolumn{2}{|c|}{$\begin{array}{l}1 \text { aluno não } \\
\text { respondeu }\end{array}$} \\
\hline 15 & $\begin{array}{l}3 \text { alunos } \\
\text { não } \\
\text { querem } \\
\text { cursar o } \\
\text { ensino } \\
\text { superior }\end{array}$ & \multicolumn{2}{|c|}{$\begin{array}{l}1 \text { aluno } \\
\text { pretende } \\
\text { fazer um } \\
\text { curso de } \\
\text { qualificação }\end{array}$} & \multicolumn{2}{|c|}{$\begin{array}{l}2 \text { alunos } \\
\text { não sabem }\end{array}$} & \multicolumn{2}{|c|}{$\begin{array}{l}6 \text { alunos } \\
\text { estão } \\
\text { divididos } \\
\text { entre } \\
2 \text { cursos }\end{array}$} & $\begin{array}{l}11 \text { c } \\
\text { têm } \\
\text { curs } \\
\text { defi }\end{array}$ & $\begin{array}{l}\text { alunos } \\
\text { h um } \\
\text { so } \\
\text { ininido }\end{array}$ & $\begin{array}{l}2 \text { alunos não } \\
\text { esponderam }\end{array}$ \\
\hline 16 & \multicolumn{10}{|c|}{ Apenas 3 alunos não definiram critérios para a escolha profissional } \\
\hline 17 & \multicolumn{3}{|c|}{$\begin{array}{l}2 \text { alunos afirmaram não } \\
\text { terem apoio }\end{array}$} & \multicolumn{4}{|c|}{$\begin{array}{l}3 \text { alunos deixaram em } \\
\text { branco }\end{array}$} & \multicolumn{3}{|c|}{$\begin{array}{l}20 \text { alunos afirmaram ter } \\
\text { apoio dos pais }\end{array}$} \\
\hline
\end{tabular}

Fonte: Autoras, 2017

De acordo com a tabela, pode-se perceber que algumas respostas se diferenciaram das respostas comumente encontradas, como a do aluno 14, que pretende se dedicar ao YouTube quando concluir o ensino médio, apontando que seu incentivo se dá por meio de pessoas que compartilham do seu trabalho. Apesar disso afirmou interesse em cursar Gestão Ambiental e como critérios para escolha foi apontada a necessidade de uma renda alta. No tocante a participação dos pais apenas acrescentou "meus pais não liga" (sic).

Três alunos apontaram querer cursar o ensino superior, apesar de dois não saberem qual curso (aluno 43 e aluna 9) e uma afirmar que não pensa nisso no momento apesar de já ter um curso em mente (aluna 36). Sendo essa mesma aluna (36) que apontou ter o apoio dos pais 
apenas em alguns momentos, pois segundo a estudante, a mãe não costuma concordar com suas decisões, colocando que o apoio dos pais acontece na direção contrária aos seus desejos.

Foi encontrado em dois alunos que não querem cursar a faculdade, o desejo de se qualificarem para o mercado de trabalho. $\mathrm{O}$ aluno 44 que já trabalha como padeiro e pretende fazer curso de qualificação em confeitaria, afirmando que sua profissão lhe dá uma boa remuneração financeira e apoio de seus pais e o aluno 42, que planeja estudar para concursos enquanto fará cursos de qualificação para o mercado de trabalho.

Entre os onze alunos que já têm um curso definido, dois não responderam o motivo para a escolha (aluno 14 e 45), o aluno 4 afirma ter escolhido por ser a área que os irmãos mais velhos trabalham, e os 8 restantes justificaram mediante identificação com a profissão ou como um sonho que nutrem desde a infância. Já entre os alunos que estão divididos entre dois cursos, apenas dois não justificaram a escolha, além disso, quatro estudantes (alunos 1 e 5, e alunas 8 e 32) estão divididos entre cursos que se encontram na mesma área do conhecimento e tem proximidades entre elas, e dois estão divididos entre profissões que divergem entre si, como Direito e Música (aluna 24) e Educação Física e Música (aluno 18).

Em relação à participação dos pais, três questionários foram deixados em branco, dois afirmaram não ter apoio e já foram apresentados nos parágrafos iniciais sendo a aluna 36 e o aluno 14. Os demais alunos evidenciaram um bom apoio paterno, apontando o valor de suporte para suas decisões, incentivo moral e financeiro. Sobre os critérios para a realização de escolha profissional, foram encontradas respostas que apontam para a necessidade de identificação com a área escolhida, realização pessoal e remuneração financeira.

Tais resultados encontrados no estilo parental indulgente, apesar de algumas contradições vistas e de respostas deixadas em branco, quando comparadas com os demais estilos apontam para uma boa realização da escolha, o que pode evidenciar que a dimensão da responsividade pode ter maior interferência na forma como os filhos lidam com a decisão profissional. Além disso, convergem para as conclusões de Magalhães, Alvarenga e Teixeira (2012), que ao comparar os estilos parentais maternos e paternos com a estabilidade de metas, apontaram que o estilo indulgente tem menor estabilidade de metas do que o estilo negligente, tendo resultados que se aproximam do estilo autoritativo. 


\section{Considerações Finais}

Sabe-se que a família é vista como principal influência na escolha profissional dos filhos adolescentes, que é o núcleo de aquisição de valores sobre o mercado de trabalho e as profissões, entretanto a família pode participar da decisão de formas distintas. A partir disso, este estudo buscou investigar a relação existente entre os estilos parentais e a escolha profissional de adolescentes jovens concludentes do ensino médio.

A análise dos resultados denota que critérios como realização pessoal e profissional, estabilidade financeira e reconhecimento são os principais itens pensados na definição da profissão, sendo que houve maior dificuldade para estabelecimento de critérios no estilo negligente. Achando-se mais claramente pensados no estilo autoritativo, seguido do indulgente.

Acerca da escolha profissional, o estilo autoritativo mostrou-se o ideal, pois os resultados apontam para uma maior definição de metas e critérios para a decisão, bem como uma expressão mais clara de sua escolha. Seguido do estilo indulgente, que apesar de algumas divergências encontradas específicas de alguns estudantes e de algumas respostas um pouco vagas, no geral também evidenciam que o apoio parental atua como facilitador do processo de definição de metas profissionais.

O estilo autoritário mostra-se como prejudicial à escolha, tendo em vista o receio que pode causar no compartilhamento da decisão do filho ao pai e na dificuldade de escolha por um curso. Já o estilo negligente apresentou dificuldades no estabelecimento de critérios que possam ser pensados na designação de uma profissão.

As divergências entre os estilos parecem convergir para o fato de que a presença ou ausência da dimensão de responsividade (apoio e orientação dos pais) seria mais relevante para a escolha do que a dimensão da exigência. No entanto, a combinação satisfatória de ambas as dimensões constituem o contexto ideal para a escolha.

Cabe ressaltar que devido o tamanho limitado da amostra da pesquisa pode ter permitido uma variação pequena entre a quantidade de estilos parentais encontrados, sugerindo-se que em pesquisas posteriores busque-se uma maior variação de participantes para uma análise mais aprofundada, bem como a utilização de novas metodologias que investiguem mais diretamente a percepção dos filhos sobre a interferência dos pais, dentre elas uma abordagem dialógica como grupos focais podem facilitar uma investigação mais minuciosa sobre fatores como 
participação dos pais e interiorização de valores do mundo do trabalho que são advindas do núcleo familiar.

\section{Referências}

AGUIAR, F. H. R.; CONCEIÇÃO, M. I. G. Orientação vocacional e promoção da saúde integral em adolescentes. Estudos e Pesquisa em Psicologia. Rio de Janeiro, v. 13, n. 1, p. 86100, 2013.

ANDRADE, M.M; et al. Adolescência, Escolha profissional e Identificação: Uma Revisão Sistemática. Id on Line Revista Multidisciplinar e de Psicologia, Julho de 2016, vol.10, n.30, Supl 3, p. 178-204 . Disponível em: <https://idonline.emnuvens.com.br/id/article/view/459/613 >. Acesso em: 25 de setembro de 2016.

BRASIL. Ministério da Saúde. Secretaria de Atenção à Saúde. Área de Saúde do Adolescente e do Jovem. Marco legal: saúde, um direito de adolescentes. Brasília : Ministério da Saúde, 2005.

BRASIL. Ministério da Saúde. Secretaria de Atenção à Saúde. Departamento de Ações Programáticas Estratégicas . Diretrizes Nacionais para a Atenção Integral à Saúde de Adolescentes e Jovens na Promoção, Proteção e Recuperação da Saúde. Brasília: Ministério da Saúde, 2010.

CONSELHO FEDERAL DE PSICOLOGIA. Adolescência e Psicologia: concepções práticas e reflexões criticas. Brasília, 2002

ERIKSON, E. O ciclo de vida completo. Porto Alegre: Artes Médicas, 1998

FEIJOO, A. M. L. C. de; MAGNAN, V. da C. Análise da Escolha Profissional:. Uma Proposta fenomenológico existencial. Psicologia Ciência e Profissão, Brasília, v. 32, n. 2, p. 356-373, 2012. Disponível em: <http://www.scielo.br/scielo.php?script=sci_arttext\&pid=S141498932012000200007\&lng=en\&nrm=iso>. Acesso em: 20 de novembro de 2016.

GIMENES, A.B. et al. Orientação profissional: uma abordagem centrada na psicanálise de famílias. $8^{\mathbf{0}}$ Congresso de extensão universitária da UNESP, p. 1-4, 2015. Disponível em: <http://hdl.handle.net/11449/142270>. Acesso em 15 de Abril de 2017.

LIMA, M. T. Orientação profissional: princípios teóricos, práticas e textos para psicólogos e orientadores. São Paulo: Vetor, 2007

MAGAlHAES, M. de O.; ALVARENGA, P.; TEIXEIRA, M. A. P.. Relação entre estilos parentais, instabilidade de metas e indecisão vocacional em adolescentes. Revista Brasileira de Orientação Profissional, São Paulo, v. 13, n. 1, p. 15-25, jun. 2012 . Disponível em: $<$ http://pepsic.bvsalud.org/scielo.php?script=sci_arttext\&pid=S167933902012000100004\&lng=pt\&nrm=iso> . Acessado em: 02 de outubro de 2016. 
MARCONI, M. de A.; LAKATOS, E. M.. Metodologia científica. 6. ed. - São Paulo : Atlas, 2011

MELO, M. C. H. de; CRUZ, G. de C. Roda de Conversa: uma proposta metodológica para a construção de um espaço de diálogo no Ensino Médio. Imagens da Educação, v. 4, n. 2, p. 3139, 2014.

NEIVA, K. M. C..Processos de escolha e orientação profissional. 2 ed. São Paulo: Vetor, 2013. p. $65-75$

OLIVEIRA, C. T. de.; DIAS, A. C. G. Percepções parentais sobre sua participação no desenvolvimento profissional dos filhos universitários. Revista Brasileira de Orientação Profissional, São Paulo , v. 14, n. 1, p. 61-72, jun. 2013 . Disponível em: $<$ http://pepsic.bvsalud.org/scielo.php?script=sci_arttext\&pid=S1679-

$33902013000100007 \& \operatorname{lng}=$ pt\&nrm=iso>. Acesso em: 02 de outubro de 2016.

PAPALIA, D. E.; OLDS, S. W.; FELDMAN, R. D. O mundo da criança: da infância à adolescência. 11. ed. - Dados eletrônicos. - Porto Alegre: AMGH, 2010.

PRATA, A. et al . O impacto dos estilos educativos parentais e do desenvolvimento vocacional no rendimento escolar de adolescentes. Análise Psicológica, Lisboa , v. 31, n. 3, p. 235243, set. $2013 \quad$. $\quad$ Disponível em <http://www.scielo.mec.pt/scielo.php?script=sci_arttext\&pid=S0870-

82312013000300002\&lng=pt\&nrm=iso>. Acesso em: 03 de outubro de 2016

PRODANOV, C. C.; FREITAS, E. C. de. Metodologia do trabalho científico: métodos e técnicas da pesquisa e do trabalho acadêmico. 2. ed. Novo Hamburgo, RS: Feevale, 2013

RAPOSO, D. M. dos S. P. Metodologia da pesquisa e da produção científica. Brasília: W Educacional, 2011.

SHAUGHNESSY, J. J.; ZECHMEISTER, E. B., ZECHMEISTER, J. S. Metodologia de pesquisa em psicologia.9 ed. Porto Alegre : AMGH, 2012.

VELHO, M. T. A. de C.; QUINTANA, A. M.; ROSSI, A. G.. Adolescência, autonomia e pesquisa em seres humanos. Rev. Bioét. , Brasília, v. 22, n. 1, p. 76-84, Abr. 2014. Disponível em: $\quad<$ http://www.scielo.br/scielo.php?script=sci_arttext\&pid=S198380422014000100009\&lng=pt_BR\&nrm=iso>. Acesso em: 02 de junho de 2017.

Como citar este artigo (Formato ABNT):

MOURA, Sâmila Landim; MARANHÃO, Thércia Lucena Grangeiro. Escolha Profissional do Adolescente Jovem: Pesqisa de Campo sobre as Interfaces do Apoio Parental. Id on Line Rev.Mult. Psic., 2018, vol.12, n.42, p. 136-157. ISSN: 1981-1179.

Recebido: 24/08/2018; Aceito: 27/08/2018 